\title{
The Relationship between the Elapsed Time from the Onset of Red Signal until Its Violation and Traffic Accident Occurrence in Abu Dhabi, UAE
}

\author{
Abdulla Alghafli ${ }^{1, *(\mathbb{D}}$, Effendi Mohamad ${ }^{2, *}$ (1) and Ahmed Al Zaidy ${ }^{3}$ \\ 1 Institute of Technology Management and Entrepreneurship, Universiti Teknikal Malaysia Melaka, \\ Melaka 76100, Malaysia \\ 2 Faculty of Manufacturing Engineering, Universiti Teknikal Malaysia Melaka, Hang Tuah Jaya, \\ Melaka 76100, Malaysia \\ 3 Traffic Engineering and Road Safety Department, Abu Dhabi Police, Abu Dhabi, United Arab Emirates; \\ al_zaidy@hotmail.com \\ * Correspondence: abdulla522@gmail.com (A.A.); effendi@utem.edu.my (E.M.)
}

Citation: Alghafli, A.; Mohamad, E.; Zaidy, A.A. The Relationship between the Elapsed Time from the Onset of Red Signal until Its Violation and Traffic Accident Occurrence in Abu Dhabi, UAE. Safety 2021, 7, 53. https://doi.org/10.3390/ safety7030053

Academic Editor: Raphael Grzebieta

Received: 26 April 2021

Accepted: 2 July 2021

Published: 6 July 2021

Publisher's Note: MDPI stays neutral with regard to jurisdictional claims in published maps and institutional affiliations.

Copyright: (c) 2021 by the authors. Licensee MDPI, Basel, Switzerland. This article is an open access article distributed under the terms and conditions of the Creative Commons Attribution (CC BY) license (https:/ / creativecommons.org/licenses/by/ $4.0 /)$.

\begin{abstract}
Few studies have been carried out in UAE relating red light violations to a number of factors, such as speed limit violations, geometric design of the intersection, and the elapsed time from the onset of red signal until the time of the violation to the occurrence of the accident. This study bridges this gap by attempting to investigate the relationship between the elapsed time from the onset of red signal and the occurrence of the accident. To achieve this objective, Poisson's regression, between occurrence of accident and elapsed time from the onset of red signal and the occurrence of the accident at various geometric designs of intersections (3-leg and 4-leg), was carried out. The research found that at 4-leg intersections, almost all red light violation related accidents occur between 1 to $2 \mathrm{~s}$ from onset of red light until its violation time. The research also showed that at 3-leg intersections, most of red light violation related accidents occur in less than $1 \mathrm{~s}$ from the onset of red light until violation time. It was also found that at lead lag signalized intersections, regardless of the type of the intersection, most accidents tend to occur between 2 to $3 \mathrm{~s}$ from the onset of red light.
\end{abstract}

Keywords: elapsed time from the onset of red signal; red light violation; logistic regression; Poisson's regression

\section{Introduction \\ 1.1. Background}

It is estimated that traffic crashes result in 20 to 50 million avoidable injuries and fatalities per year [1]. Red light violation has been and is still considered one of the major factors resulting in traffic accidents around of the world. Some of these traffic accidents turn out to be fatal while others result in significant property damage. In United Arabs Emirates' cities, such as Dubai, red light violations contributed to $46 \%$ of road traffic accidents in 2016 [2]. In 2011, the United Arabs Emirates' national average of traffic accidents associated with red light violations was approximately 6\% [2]. This is a huge percentage to be contributed by factor alone. In United States, for instance, red light running (red light violation) resulted in 697 fatalities in 2013 [3]. During the same time, approximately 127,000 people sustained severe injuries as a result of red-light violations [4]. In 2012, 683 individuals lost their lives as a result of red light violations and 133,000 people sustained serious injuries in the United States of America [5]. In 2015, more than 771 individuals lost lives in the United States as a result of traffic accidents involving red light violations [6]; 137,000 were seriously injured as result of red light violations in the same period [6]. In the United Kingdom, 140,000 traffic accidents occurred in 2015 as a result of traffic violations [6]; these accidents resulted in more than 1730 fatalities and over 186,000 people sustained serious injuries [6]. 
Regardless of red light violations contributing significantly towards traffic accidents in United Arabs Emirates (UAE), to the best of the authors' knowledge, not many studies have been carried out in UAE relating red light violations to a number of factors, such as speed limit violations, geometric design of the roads, and the relationship between the elapsed time from the onset of red signal until the time of the violation, and the occurrence of the accident. This study bridges this gap by attempting to investigate the relationship between the elapsed time from the onset of red signal until the time of the violation and the occurrence of the accident.

\subsection{Literature Review}

\subsubsection{Red Light Running}

Red light running (RLR), according to Cohn et al. [6], Zhang et al. [4], Goldenbeld [3] and Jantosut et al. [7], is a situation where a driver, cyclist or motorcyclist enters an intersection at any time after the red light signal has already turned red. A vehicle, motorcyclist or cyclist is considered to have entered an intersection when they cross the stop line on the intersection [3]. Red light running or violation also applies to pedestrians. However, there are exceptions to this definition. For instance, road users who are unintentionally in the intersection when the signal changes to red, such as those waiting to turn left, are not considered red light violators or red light runners [3,8-10].

\subsubsection{Red Light Camera System}

It is without doubt that RLR is a major cause of road accidents around the world [6]. As result, there is a need for reducing such types of accidents. Research has shown that removing traffic violations can reduce injury associated with traffic accident by as much as 40 percent [6]. One of ways through which authorities reduce RLR is by installation of RLR camera detection systems at signalized junctions (intersections).

The main objective of installing RLR camera systems, as noted by Baratian-Ghorghi et al. [11], is improving intersections' safety by capturing the details of red light runners using a camera-computer system. Red light cameras, as noted by Cohn et al. [6] and Baratian-Ghorghi et al. [11], are automated photo detection systems designed to capture images (photos) of red light runners (violators). They mainly consist of three elements, namely: a computer, cameras, and sensors (also known as triggers) $[3,12,13]$. The camera may take video images or still images [6]. These cameras may be installed on all arms (or corners) of an intersection in such a way that vehicles approaching the intersection from any direction can be photographed from a number of angles $[6,14]$. They may also be installed on one arm of an intersection where red light running is most rampant [6].

\subsubsection{Effectiveness of Red Light Camera System}

Effectiveness of RLR camera systems in preventing accidents is often evaluated (measured) by examining the reduction in the crash (accident) frequencies (or average number of crashes) when before and after installation (of the camera system) crash frequencies are compared. In this technique, comparison of the total accidents before and after installation of the camera system is used to determine the effectiveness of the system. This technique was employed by Walden [15] when the researcher evaluated the effectiveness of enforcement of RLR camera systems in Texas. Walden [15] found that one year after installation of the automated camera system, traffic crashes at signalized junctions reduced by more than $23 \%$. In the second year, the reduction was $27 \%$ when compared to the year 1 reduction. In third year, Walden (2011) recorded a $21 \%$ reduction in crashes associated with red light violation.

When evaluating implantation of automated traffic camera systems in Iowa, Hallmark et al. [16] found that this system resulted in a reduction of red light running crashes by over $40 \%$ in non-rear end crashes per quarter (every 3 months). This was found after comparing the frequency of these types of accidents before and after the cameras were installed. 
In another study, while investigating the effect of installing camera systems on reduction of RLR in Arlington County, Virginia, MaCartt and Wu [17] found that installation of a camera system resulted in a 39\% reduction of RLR occurring at least $0.5 \mathrm{~s}$ after the start of the red light. They also found that this system resulted in $86 \%$ violations occurring more than $1.5 \mathrm{~s}$ after the light turning red.

When evaluating the impact of implementation of red light camera systems as a way of reducing traffic accidents within Miami-Dade County, Florida, Llau et al. [18] found that within one year, the system resulted in more than a $40 \%, 3 \%$, and $19 \%$ reduction in rear end crashes, right angle turn crashes, and a reduction in injuries associated with these types of crashes, respectively.

Park et al. [19] evaluated the effectiveness of automated camera systems by comparing crash frequencies before and after implementation of RLR camera systems. Twenty-four out of 27 intersections involved in this study recorded a reduction in side impact crashes [19]. Ten out the 27 intersections, however, recorded an increase in rear end accidents when automated camera systems were installed [19].

\subsubsection{Factors That Affect Red Light Running}

Red light violation is often affected by a number of factors: demographic factors, such as driver age, occupancy and seat belts; human behavioral factors, such as speeding; unintentional factors, such as drowsiness and distraction; vehicular characteristics; and characteristics of the intersection [20]. Younger drivers are more likely to be involved in RLR when compared to older ones. Drivers are also more likely to be involved in RLR when alone in the vehicle [20].

\subsubsection{The General Techniques Used in Evaluating Factors Influencing Traffic Safety}

Factors affecting traffic safety can be examined using a number of techniques, some of which are: logistic regression model and Poisson regression model [20]. These two regression models are discussed in detail as below.

\subsection{Logistic Regression Model}

To the best knowledge of the authors, there are no studies that have directly determined the relationship between the elapsed time from the onset of red signal until the time of the violation and the occurrence of the accident; however, this relationship has been studied indirectly by the previous researchers. For example, a study by Bonneson, et al. [20] studied the relationship between elapsed time until the start of red-light and RLR. The study found that most of the RLR (94.2\%) occur within the $2.0 \mathrm{~s}$ after the start of red light [20]. The study also found that half of the RLR occur within the first 0.5 after the onset of red light [20]. A study by McCartt and Hu [20], which employed logic regression in determining the relationship between time period from onset of red light to the violation found that 39\% red light violations (and consequently accidents associated with them) occur at approximately $0.5 \mathrm{~s}$ from the onset of red light. The study also found that $86 \%$ of the red light violations occur within $1.5 \mathrm{~s}$ from the start of red light.

A study by Yang and Najm [21] also employed logistic regression to evaluate the relationship between red light violations and elapsed time from onset of red light until violation, and a number of factors, such as driver age, intersection type and environmental factors. Two logistic regressions models were developed by the researchers since there were two dependent variables, and the objective of the study was to determine the relationship between, age, vehicle year, violation location and violation time on the two dependent variables: (a) "elapsed time between the onset of red signal and the time of violation" and (b) the speed of the vehicle. The study found that $94 \%$ of the red-light violationrelated accidents occurred within $2 \mathrm{~s}$ after red light onset. The study also recorded only $3 \%$ violation-related accidents occurred $5 \mathrm{~s}$ after the red light onset [22]. The study also found that young drivers (30 years and below) were more likely to run the red light [22]. 
The typical logistic model employed by Yang and Najm [21] is shown in Equations (1) and (2). In their research, Yang and Najm [21] had two dependent variables: (1) Elapsed time from the onset of red signal, and (2) average speed at the violation. The explanatory (independent) variables were accident occurrence, geometrical and other operational characteristics of the intersections. Since there are two dependent variables, which are dichotomous, logistic regression is proposed. The model is stated below.

$$
\begin{aligned}
p_{i} & =\frac{e^{\left(\alpha+\beta_{1} X_{i 1}+\beta_{2} X_{i 2}+\ldots . \beta_{k} X_{i k}\right)}}{1+e^{\left(\alpha+\beta_{1} X_{i 1}+\beta_{2} X_{i 2}+\ldots . \beta_{k} X_{i k}\right)}} \\
p_{i} & =\frac{1}{1+e^{-\left(\alpha+\beta_{1} X_{i 1}+\beta_{2} X_{i 2}+\ldots \beta_{k} X_{i k}\right)}}
\end{aligned}
$$

i. $\quad P i=$ Depend variable $=$ probability of yi which is equal 1: In the case of Yang and Najm [20], " $\mathrm{Pi}=1$ ( 1 = speed of the violating vehicle > PSL (Posted Speed Limit) or elapsed time since the onset red light $>2 \mathrm{~s}$ when violator ran red light)" (p 30). In summary, there are two dependent variables:

a. Speed of the violating vehicle when the light violation took place (whether it was above or below the posted speed limit)

b. Elapsed time since the onset red light

i. $\quad \alpha=$ Constant term.

ii. $\quad \beta=$ Coefficients associated with explanatory variables (independent variable) $\mathrm{x} 1$ to $x k$. In the case of Yang and Najm [21]), the explanatory (independent variables constituted: age, vehicle year, gender of the driver, violation location and violation time).

iii. $\quad \mathrm{i}=1, \ldots \ldots \mathrm{n}$ individuals.

Yang and Najm [21] explained that logistic regression analysis is employed in such kind of cases since the two dependent variables are dichotomous.

\subsection{Poisson Regression}

Logistic regression is only applicable in cases where dependent variables are binary. In cases where dependent variables are binary, other types of crash-based regression models can be employed. These regression models are: multiple linear regression, nested logit regression, negative binomial regression and Poisson's regression [22]. Abdel-Aty et al. [22] employed negative binomial regression in examining the correlation between road traffic accidents and factors believed to be contributing towards the crashes. Poisson regression can also be used to examine the occurrence of road crashes and its association with road conditions (wet or dry), driver experience, driver age, road geometric conditions, and other factors [23]. For instance, Cai [24] employed Poisson lognormal regression model to carry out a comparative study on several crash-based issues with intension of providing safety guidance in the planning of Florida roads so as to enhance safety.

A typical example of Poisson's regression model is shown in Equation (3). In this regression model, the dependent variable is assumed to follow Poisson distribution. Additionally, all other variables are assumed to be independent [25]. It is defined as shown in Equation (3).

$$
\lambda i=\beta x i+\varepsilon
$$

In this equation:

$\lambda i=$ frequency of traffic accident occurrence at time $t$ interval;

$x i=$ factors being examined for their influence on accident occurrence;

$\beta=$ vector parameter;

$\varepsilon=$ error variable (error term).

The error term $(\varepsilon)$ exponential value is assumed to have a gamma distribution with a mean of 1 and a variance of $\alpha 2$ [26]. 
Probability distribution associated with $\mathrm{k}$ number accident occurrences at time $\mathrm{t}$ interval is given by:

$$
\operatorname{Pi}(k)=[(e(\lambda i) t) \times(\lambda i) k] \div k
$$

In this equation:

$\mathrm{k}=$ Accident occurrence at $\mathrm{t}$ time interval [27];

$\mathrm{e}=$ exponential factor

The relationship between elapsed time from onset of red light until time of violation and occurrence of crashes as already mentioned was determined using Poisson's regression with accident occurrence as the dependent variable. The independent variables for these regression models were the various elapsed times from the onset of red light to violation. These elapsed times included sum of less $1 \mathrm{~s}$ elapsed times, sum of 1 to $2 \mathrm{~s}$ elapsed times, sum of 2 to $3 \mathrm{~s}$ elapsed times, sum of 3 to $4 \mathrm{~s}$ elapsed times, and sum of greater than $4 \mathrm{~s}$ elapsed times. The regression analyses were carried out at different geometric configuration of the intersections (4-leg, 3-leg, and different configurations) and at different signal controls (split and lead lag) signal controls.

\section{Materials and Methods}

Poisson's regression was used to determine the relationship between time from onset of red light until red light violation and occurrence of crashes. The research also examined the effects of traffic volume on the red light violation, relationship between red light violation, and accident severity (fatality and property damage). Considered were the effect of speed on red light violation with and without crashes. Poisson regression was used because in determining the relationship between time from onset of red light until time of violation and occurrence of crashes, the time lapse (time from onset of red light until time of violation) data was not binary but continuous. Accident occurrence data is also continuous. Additionally, Poisson's regression has been employed in the past by many researchers in determine traffic occurrence and road geometric factors. For instance, Joshua and Garber [28] used linear regression and Poisson's regression to investigate the correlation between road geometric factors and occurrence of accidents. They noted that of the two models, linear regression accurately determined the required correlation.

\subsection{Data Source and Type}

The data used in this study were collected from Abu Dhabi Traffic Police accident database. The data included the occurrence of accidents, red light violations, elapsed time from the start of red signal to violation, and speed at the time of violation of red light at 3-leg and 4-leg intersections in Abu Dhabi. These data were for 33 4-leg intersections, 11 3-leg intersections, and 5 different types of intersections, which gives a total of 49 intersections. The traffic controls in these intersections were either lead lag or split phasing. Of these controls 30 were lead lag phasing control systems and 19 were split phasing type of signal control. The data covered a period of 5 years from 2015 to 2020 . The red light violations between 2015 and 2020 in these intersections ranged from 3 violations in some intersections, such as intersection 10A, to 7321 violations in intersection 71 .

The elapsed time from the start of red light to RLR is measured using image processing technique that uses red-light violation cameras to automatically record vehicle license plates during red light violations.

\subsection{Research Limitation}

The study employed an archival research strategy since the data used were obtained from government archives and no primary data was collected. The limitation of this strategy is that the authors did not participate in the collection of data and thus their inputs as well as issues encountered during data collection were not accounted for during data collection. It is, therefore, proposed that future studies consider collecting up to date primary data as opposed to secondary data. 


\subsection{Validity and Reliability}

The research employed Poisson's regression model in determining the relationship between elapsed time from red light onset and accident occurrence. This method has been applied by many previous researchers and has been proven to be reliable and valid. Additionally, all the steps followed in achieving the objectives of the study have been stated in the article.

\section{Results and Discussion}

\subsection{Descriptive Statistics}

Tables 1-3 above show the summary statistics of red light violations, severe accidents, total accidents, and associated property damage at different intersections. The results above show that red light violations are highest (2870 each) in different types of intersections despite the fact that they had the least observations (5 compared to 33 in 4-leg intersection but only accounted for 1297). In terms of total accidents, 4-leg intersections accounted for 5.8 accidents each during the study period. In terms of more property damge, 3-leg intersection contributed the most with an average of 1.64 per intersection. In terms of severe accidents, 4-leg intersection contributed the most with an average of 4.9 per intersection.

Table 1. 4-leg intersections summary statistics.

\begin{tabular}{cccccc}
\hline Variable & Obs & Mean & Std. Dev. & Min & Max \\
\hline Total Accidents & 33 & 5.82 & 5.79 & 0 & 22 \\
Accidents associated & 33 & 0.91 & 1.16 & 0 & 5 \\
with property damage & 33 & 4.91 & 5.34 & 0 & 21 \\
Severe Accidents & 33 & 1297.33 & 1179.77 & 3 & 4599 \\
No. of violations & & &
\end{tabular}

Table 2. 3-leg intersections summary statistics.

\begin{tabular}{cccccc}
\hline Variable & Obs & Mean & Std. Dev. & Min & Max \\
\hline Total Accidents & 11 & 3.82 & 3.82 & 0 & 10 \\
Accidents associated & 11 & 1.64 & 2.80 & 0 & 9 \\
with property damage & 11 & 2.18 & 2.36 & 0 & 7 \\
Severe Accidents & 11 & 1789 & 1153.38 & 185 & 3709 \\
No. of violations & 11 & & \\
\hline
\end{tabular}

Table 3. Different intersection summary statistics.

\begin{tabular}{cccccc}
\hline Variable & Obs & Mean & Std. Dev. & Min & Max \\
\hline Total Accidents & 5 & 3.60 & 2.88 & 0 & 6 \\
Accidents associated & 5 & 0.40 & 0.55 & 0 & 1 \\
with property damage & 5 & 3.20 & 2.59 & 0 & 6 \\
Severe Accidents & 5 & 2870.20 & 2831.71 & 247 & 7321 \\
No of violations & 5 &
\end{tabular}

\subsection{Crash with Red Light Running}

From Table 4, it is observed that in 4-leg and 3-leg intersections, red light running (RLR) is positively correlated with total accidents. Red light running is also positively correlated with severe accidents, which means the higher the RLR, the higher the number of severe accidents. Red light violation is also positively correlated with property damage, which is an indication that the higher RLR, the higher the instances of property damage. In some countries, such as France, red light violation does not seem to be a major factor causing accidents at the intersections [29]. In this country, traffic accidents at the intersections are relatively low despite the large RLR [29]. 
Table 4. Correlation between red light violations and different types of accidents.

\begin{tabular}{|c|c|c|c|}
\hline & (1) & (2) & (3) \\
\hline Variables & 4-Leg & 3-Leg & $\begin{array}{c}\text { Different } \\
\text { intersection }\end{array}$ \\
\hline Total Accidents & $\begin{array}{l}0.01 * \\
{[0.00]}\end{array}$ & $\begin{array}{l}0.11^{* * *} \\
{[0.00]}\end{array}$ & $\begin{array}{c}-0.73^{* * *} \\
{[0.02]}\end{array}$ \\
\hline Severe Accidents & $\begin{array}{c}0.04^{* * *} \\
{[0.01]}\end{array}$ & $\begin{array}{c}0.01 \\
{[0.01]}\end{array}$ & $\begin{array}{c}0.56^{* * *} \\
{[0.02]}\end{array}$ \\
\hline $\begin{array}{c}\text { Property Damage } \\
\text { Accidents }\end{array}$ & $0.05^{* * *}$ & 0.07 & 0.09 \\
\hline & {$[0.01]$} & [0.03] & {$[0.05]$} \\
\hline Fatal Accidents & $\begin{array}{c}0.25^{* * *} \\
{[0.01]}\end{array}$ & $\begin{array}{c}-2.81^{* * * *} \\
{[0.08]}\end{array}$ & $\begin{array}{l}-2.40 * * * \\
{[0.04]}\end{array}$ \\
\hline Constant & $\begin{array}{c}6.83^{* * *} \\
{[0.01]}\end{array}$ & $\begin{array}{c}7.22 * * * \\
{[0.01]}\end{array}$ & $\begin{array}{l}8.93 * * * \\
{[0.01]}\end{array}$ \\
\hline $\begin{array}{c}\text { Number of sites } \\
\text { investigated }\end{array}$ & 33 & 10 & 5 \\
\hline Standard errors in brac & & & \\
\hline
\end{tabular}

In different types of intersections (roundabout and others), RLR and total accidents are negatively correlated. However, the RLR is positively correlated with severe accidents.

The results also show that accident fatality seems to be positively related with red light violations at 4-leg intersections. In 3-leg and different intersection types, however, the relationship between red light violation and accident fatality is negative. This difference in result may be associated with the observations. For different types of intersections, only 5 observations were considered, and in 3-leg intersections, only 10 observations were considered. Overall, these results show that the most dangerous intersections in Abu Dhabi are 4-leg intersections.

\subsection{Red Light Running without Crash}

Table 5 above shows the relationship between RLR (red light running) and speed when without a crash. The results show a positive relationship between these variables. This indicates that even if crash has not occurred, average speed is still a major contributor towards red light violations. Therefore, one way of avoiding RLR is by introducing lower speed limits at the intersections, especially at the 3-leg and 4-leg intersections.

Table 5. Relationship between red light violation with speed.

\begin{tabular}{ccc}
\hline & $\mathbf{( 1 )}$ & $\mathbf{( 2 )}$ \\
\hline Variables & 4-Leg intersection & 3-leg intersection \\
Average of Speed & $-0.06^{* * *}$ & $-0.14^{* * *}$ \\
& {$[0.00]$} & {$[0.01]$} \\
Constant & $9.52^{* * *}$ & $14.21^{* * *}$ \\
& {$[0.15]$} & {$[0.25]$} \\
Number of sites investigated & 5 & 4 \\
\hline
\end{tabular}

*** $p<0.01$.

\subsection{Red Light Running with Crash}

Table 6 shows the relationship between RLR (red light running) and speed accompanied by crash. The results show a negative relationship between RLR and speed. This result as well as the previous result (relationship between RLR and speed not accompanied by crash) indicate that regardless of whether a traffic accident occurs or not, speed at which a vehicle approaches an intersection has a major contribution towards RLR. This is such that the higher the average approach speed, the higher the red light violations. Therefore, red light violations can be reduced by introducing a lower speed limit at the intersections. 
Table 6. Relationship between red light violation with speed with crashes.

\begin{tabular}{cccc}
\hline & $\mathbf{( 1 )}$ & $\mathbf{( 2 )}$ & $\mathbf{( 3 )}$ \\
\hline Variables & $4-\mathrm{leg}$ & $3-\mathrm{leg}$ & Different intersection \\
Average Speed & $0.01^{* * *}$ & $-0.01^{* * *}$ & $0.07^{* * *}$ \\
& {$[0.00]$} & {$[0.00]$} & {$[0.00]$} \\
Constant & $6.59^{* * *}$ & $8.04^{* * *}$ & $3.63^{* * *}$ \\
Number of sites & {$[0.02]$} & {$[0.05]$} & {$[0.10]$} \\
investigated & 28 & 7 & 4 \\
F** $^{*}<0.01$ & & &
\end{tabular}

\subsection{Red Light Violation and Traffic Volume}

Table 7 shows the relationship between RLR and traffic volume. The results indicate a negative correlation between RLR and traffic volume. This is an expected result. Higher traffic volume results in a reduction in traffic speed and also consumes space at the intersection. Therefore, those wishing to run a red light have no space to do so.

Table 7. Relationship between red light violation and traffic volume.

\begin{tabular}{cccc}
\hline & $\mathbf{( 1 )}$ & $\mathbf{( 2 )}$ & $\mathbf{( 3 )}$ \\
\hline Variables & $4-\mathrm{leg}$ & $3-\mathrm{leg}$ & Different intersection \\
Average Speed & $0.01^{* * *}$ & $0.02^{* * * *}$ & $0.07^{* * *}$ \\
Traffic volume & {$[0.00]$} & {$[0.00]$} & {$[0.00]$} \\
& $-0.00^{* * *}$ & $-0.01^{* * *}$ & $-0.01^{* * *}$ \\
Constant & {$[0.00]$} & {$[0.00]$} & {$[0.00]$} \\
& $7.25^{* * *}$ & $6.31^{* * *}$ & $12.79^{* * *}$ \\
Number of sites & {$[0.03]$} & {$[0.06]$} & {$[0.12]$} \\
investigated & 27 & 6 & 3 \\
F*** $_{*}<0.01$ & & &
\end{tabular}

\subsection{Relationship between Elapsed Time from Red Light Onset and Accident Occurrence}

The results of the regression analysis of the relationship between elapsed time from red light onset and accident occurrence at different geometric configurations of the intersections (4-leg, 3-leg, and different types of intersection) and at different signal controls (lead lag and split) are shown in Table 8 below.

\subsubsection{At 4-Leg Intersection}

The results of the relationship between elapsed time from onset of red light until time of violation and traffic accident occurrence at 4-leg intersection are shown in Table 1 (regression result 1). At 4-leg intersection, a positive correlation between " 1 to $2 \mathrm{~s}$ from the onset of red light until its violation" and the traffic accident occurrence is observed. It is also observed that there is no relationship between other elapsed times from the onset of red light until violation ( $<1 \mathrm{~s}, 2$ to $3 \mathrm{~s}, 3$ to $4 \mathrm{~s}$, and $>4 \mathrm{~s})$ and the traffic accident. This means that at 4-leg intersections, almost all red light violation related accidents occur between 1 to $2 \mathrm{~s}$ from onset of red light until its violation time, and almost none of these accidents occur at $<1 \mathrm{~s}, 2$ to $3 \mathrm{~s}, 3$ to $4 \mathrm{~s}$, and $>4 \mathrm{~s}$ from onset of red light until violation time.

This result seems similar to results found by Yang and Najm [21], who instead of using Poisson's regression model employed logit regression to evaluate the relationship between RLR and elapsed time from start of red light until violation, and considered driver age, intersection type, and environmental factors. The study found that $94 \%$ of the red light violation related accidents occurred within $2 \mathrm{~s}$ after red light onset. The study also found that only $3 \%$ of red light violation related accidents occurred $5 \mathrm{~s}$ after the red light onset. The results of another study carried out by Bonneson et al. [19] also coincide with the results of this study despite using a different technique (logistic regression). The study 
found that most of the red light violations $(94.2 \%)$ and consequently accidents associated with red light violations occur within the $2.0 \mathrm{~s}$ after the start of red light [19]. The study also found that half of the RLR often occur within the first $0.5 \mathrm{~s}$ after the onset of red light [19]. Accordingly, this means that most accidents also occur within the first $2 \mathrm{~s}$ after the start of red light signals.

Table 8. Poisson regression results for the relationship between elapsed time from red light onset and accident occurrence.

\begin{tabular}{|c|c|c|c|c|c|}
\hline & (1) & (2) & (3) & (4) & (5) \\
\hline Variables & 4-Leg & 3-Leg & Different & Lead lag & Split \\
\hline \multirow{2}{*}{ Sum of $<1$ s } & -0.01 & $0.05 * *$ & -1.74 & 0.00 & -0.00 \\
\hline & {$[0.00]$} & {$[0.01]$} & [44.04] & {$[0.00]$} & {$[0.00]$} \\
\hline \multirow[t]{2}{*}{ Sum of 1 to $2 \mathrm{~s}$} & $0.01 * *$ & 0.00 & -1.41 & -0.00 & -0.00 \\
\hline & {$[0.00]$} & {$[0.00]$} & [36.12] & {$[0.00]$} & {$[0.00]$} \\
\hline \multirow{2}{*}{ Sum of 2 to $3 \mathrm{~s}$} & -0.01 & -0.01 & 4.31 & $0.01 * *$ & -0.01 \\
\hline & {$[0.00]$} & {$[0.00]$} & [110.29] & {$[0.00]$} & {$[0.00]$} \\
\hline \multirow[t]{2}{*}{ Sum of 3 to $4 \mathrm{~s}$} & 0.01 & -0.01 & -9.08 & $-0.02^{* * *}$ & 0.01 \\
\hline & {$[0.01]$} & {$[0.02]$} & [232.34] & {$[0.01]$} & {$[0.01]$} \\
\hline \multirow[t]{2}{*}{ Sum of $>4 \mathrm{~s}$} & 0.00 & -0.01 & & -0.00 & 0.00 \\
\hline & {$[0.00]$} & {$[0.00]$} & & {$[0.00]$} & {$[0.00]$} \\
\hline \multirow[t]{2}{*}{ Constant } & -0.00 & $1.04 * *$ & 105.52 & $1.51^{* * *}$ & $1.05^{* * *}$ \\
\hline & {$[0.00]$} & {$[0.42]$} & [2620.13] & {$[0.15]$} & {$[0.23]$} \\
\hline \multirow{2}{*}{ Traffic Volume } & $-0.01^{* * *}$ & $-0.01^{* * *}$ & $0.00 * * *$ & 0.00 & $0.00^{* * *}$ \\
\hline & [0.00] & [0.01] & {$[0.00]$} & {$[0.00]$} & {$[0.00]$} \\
\hline \multirow[t]{2}{*}{ Property damage } & $0.50^{* * *}$ & $0.62 * * *$ & $0.32 * *$ & $0.12^{* *}$ & $0.02^{* * * *}$ \\
\hline & {$[0.07]$} & {$[0.07]$} & {$[0.04]$} & {$[0.02]$} & {$[0.04]$} \\
\hline \multirow[t]{2}{*}{ Speed } & $0.05^{* * *}$ & $0.08^{* * *}$ & $0.05^{* * *}$ & $0.07^{* * *}$ & $0.04^{* * *}$ \\
\hline & {$[0.01]$} & {$[0.04]$} & {$[0.02]$} & {$[0.06]$} & [0.02] \\
\hline $\begin{array}{l}\text { Number of sites } \\
\text { investigated }\end{array}$ & 30 & 11 & 5 & 29 & 17 \\
\hline
\end{tabular}

\subsubsection{At 3-Leg Intersection}

The regression results of the relationship between elapsed time from start of red light until RLR and traffic accident occurrence at 3-leg intersection are shown in Table 1. Observed at the 3-leg intersection, there is a positive and significant (coefficient value is 0.033 ) relationship between "less than $1 \mathrm{~s}$ from the onset of red light until" its violation and the traffic accident occurrence. The results also show that there is no relationship between other elapsed times from the onset of red light until its violation (1 to $2 \mathrm{~s}, 2$ to $3 \mathrm{~s}$, 3 to $4 \mathrm{~s}$, and $>4 \mathrm{~s}$ ) and the traffic accident occurrence. This means that at 3-leg intersections most red light violation related accidents occur less than $1 \mathrm{~s}$ from the onset of red light. Just as in 4-leg intersections, this result is similar to results of Yang and Najm [21] and Bonneson, et al. [19] who used logit regression to evaluate the correlation between RLR and elapsed time from the start of red light until violation, and found that $94 \%$ of the red light violation related accidents occurred within $2 \mathrm{~s}$ of red light onset.

\subsubsection{At Signalized Intersection}

Table 8 (regression results 3 and 4) show the regression results of the relationship between elapsed time from onset of red light until its violation and traffic accident occurrence at lead lag and split signalized intersections. Observed at lead lag signalized intersections (regardless of the type of intersection), there is a positive and significant relationship between 2 to $3 \mathrm{~s}$ from the onset of red light until its violation and the traffic accident occurrence. This result shows that at lead lag signalized intersections, regardless of the type of the intersection, most accidents tend to occur between 2 to $3 \mathrm{~s}$ from the onset of red light. The results, however, show a negative relationship between 3 to $4 \mathrm{~s}$ from the onset of red light until its violation and the traffic accident occurrence. This means that after $3 \mathrm{~s}$ since the onset of red light, no or very few accidents occur at lead lag signalized 
intersections. The reason for this may be that after $3 \mathrm{~s}$, the driver might have cleared the intersection and is already out of danger (out of the intersection).

It is without doubt that in United Arabs Emirates cities, such as Dubai, red light violations contributed to $46 \%$ of road traffic accidents in 2016 [1,30]. From the above results, it is observed that these red light running results into traffic crashes, which may result into property damage, injury or even death. These can be reduced by implementing camera systems in Abu Dhabi intersections. Studies by Walden [14] and Carnis [31] have shown that implementation of camera system can significantly reduce traffic accidents and their associated injuries at intersections.

\section{Conclusions}

Red light violations contribute significantly towards traffic accidents in United Arabs Emirates (UAE). It is, however, the occurrence of traffic accidents at signalized intersections that is often affected by elapsed time from the onset of red light until its violation. In this regard, the research found that at 4-leg intersections, almost all red light violation related accidents occur between 1 to $2 \mathrm{~s}$ from onset of red light until its violation time; almost none of these accidents occur at $<1 \mathrm{~s}, 2$ to $3 \mathrm{~s}, 3$ to $4 \mathrm{~s}$, and $>4 \mathrm{~s}$ from onset of red light until violation time. At 3-leg intersections, most of red light violation related accidents occur in less $1 \mathrm{~s}$ from the onset of red light until violation time. At lead lag signalized intersections, regardless of the type of the intersection, most accidents tend to occur between 2 to $3 \mathrm{~s}$ from the onset of red light. The results also show that after $3 \mathrm{~s}$, from the onset of red light, no or very few accidents occur at lead lag signalized intersections.

Author Contributions: Conceptualization, A.A.; Data curation, A.A. and A.A.Z.; Formal analysis, A.A.; Methodology, A.A.; Project administration, A.A.Z.; Supervision, E.M.; Writing-original draft, A.A. All authors have read and agreed to the published version of the manuscript.

Funding: This research was funded by Universiti Teknikal Malaysia Melaka, grant number FRGS/1/2020/ TK0/UTEM/02/42.

Institutional Review Board Statement: Not applicable.

Informed Consent Statement: Not applicable.

Data Availability Statement: Data used in this study were obtained from Abu Dhabi Police and Department of Transport (DoT). Abu Dhabi Police through Federal Traffic Database provided accident occurrence data.

Acknowledgments: The authors are grateful to the Malaysian Government, Universiti Teknikal Malaysia Melaka (UTeM) for providing all the support to conduct this research and To Abu Dhabi Police (Traffic Engineering Department) for providing the requested data.

Conflicts of Interest: The authors declare no conflict of interest.

\section{References}

1. Ellison, A.B.; Greaves, S.P.; Bliemer, M.C. Driver behaviour profiles for road safety analysis. Accid. Anal. Prev. 2015, 76, 118-132. [CrossRef] [PubMed]

2. Goldenbeld, C. Traffic Rule Violations—-Red light Running Driving/Riding Through an Intersection or Crossing the Road when the Light is on Red. SWOV Inst. Road Saf. Res. 2016, 1, 1-25.

3. Zhang, Y.; Yan, X.; Li, X.; Wu, J.; Dixit, V.V. Red-light-running crashes' classification, comparison, and risk analysis based on General Estimates System (GES) crash database. Int. J. Environ. Res. Public Health 2018, 15, 1290. [CrossRef]

4. Jahangiri, A.; Rakha, H.; Dingus, T.A. Red-light running violation prediction using observational and simulator data. Accid. Anal. Prev. 2016, 96, 316-328. [CrossRef]

5. Cohn, E.G.; Kakar, S.; Perkins, C.; Steinbach, R.; Edwards, P. Red light camera interventions for reducing traffic violations and traffic crashes: A systematic review. Campbell Syst. Rev. 2020, 16, e1091. [CrossRef]

6. Jantosut, P.; Satiennam, W.; Satiennam, T.; Jaensirisak, S. Factors associated with the red-light running behavior characteristics of motorcyclists. IATSS Res. 2020. In Press. [CrossRef]

7. Bai, L.; Sze, N. Red light running behavior of bicyclists in urban area: Effects of bicycle type and bicycle group size. Travel Behav. Soc. 2020, 21, 226-234. [CrossRef] 
8. Shaaban, K.; Gharraie, I.; Sacchi, E.; Kim, I. Severity analysis of red-light-running-related crashes using structural equation modeling. J. Transp. Saf. Secur. 2019, 13, 1-20. [CrossRef]

9. Cortês, A.R.P.; Moreira, C.A.; Paes, R.A.S.; Veloso, D.I.K. Geophysical and metalogenetic modelling of the copper occurrence in Camaquã Sedimentary Basin, Brazilian Southern. Pure Appl. Geophys. 2019, 176, 4955-4968. [CrossRef]

10. Baratian-Ghorghi, F.; Zhou, H.; Wasilefsky, I. Effect of red-light cameras on capacity of signalized intersections. J. Transp. Eng. 2016, 142, 04015035. [CrossRef]

11. Goldenbeld, C.; Daniels, S.; Schermers, G. Red light cameras revisited. Recent evidence on red light camera safety effects. Accid. Anal. Prev. 2019, 128, 139-147. [CrossRef]

12. McBride, H.D. Developing an Objective Warrant System for Red Light Cameras. Ph.D. Thesis, University of New Brunswick, Fredericton, Canada, 2019.

13. Fu, C.; Liu, H. Investigating influence factors of traffic violations at signalized intersections using data gathered from traffic enforcement camera. PLoS ONE 2020, 15, e0229653. [CrossRef]

14. Walden, T.D. Evaluation of Photographic Traffic Signal Enforcement Systems in Texas; Crash Analysis Program-Center for Transportation Safety: College Station, TX, USA, 2011.

15. Hallmark, S.; Orellana, M.; McDonald, T.; Fitzsimmons, E.; Matulac, D. Red light running in Iowa: Automated enforcement program evaluation with Bayesian analysis. Transp. Res. Rec. 2010, 2182, 48-54. [CrossRef]

16. McCartt, A.T.; Hu, W. Effects of red light camera enforcement on red light violations in Arlington County, Virginia. J. Saf. Res. 2014, 48, 57-62. [CrossRef] [PubMed]

17. Park, S.Y.; Lan, C.-L.; Chang, G.L. Evaluating the Impacts of Red Light Camera Deployment on Intersection Traffic Safety; State Highway Administration, Office of Policy \& Research: Maryland, MD, USA, 2018.

18. Walden, T.D. Analysis of the Effectiveness of Photographic Traffic Signal Enforcement Systems in Texas; Crash Analysis Program-Center for Transportation Safety: College Station, TX, USA, 2008.

19. Bonneson, J.A.; Zimmerman, K.; Brewer, M.A. Engineering Countermeasures to Reduce Red-Light-Running Fatalities; Texas Transportation Institute: College Station, TX, USA, 2009.

20. Ouni, F.; Belloumi, M. Modeling traffic accident occurrence at hazardous road locations: A case study in Tunisia. Soc. Sci. 2018, $1,315$.

21. Yang, C.D.; Najm, W. Analysis of Red Light Violation Data Collected from Intersections Equipped with Red Light Photo Enforcement Cameras; CreateSpace Independent Publishing Platform: Scotts Valley, CA, USA, 2006.

22. Abdel-Aty, M.A.; Radwan, A.E. Modeling traffic accident occurrence and involvement. Accid. Anal. Prev. 2000, 32, 633-642. [CrossRef]

23. Miaou, S.-P. The relationship between truck accidents and geometric design of road sections: Poisson versus negative binomial regressions. Accid. Anal. Prev. 1994, 26, 471-482. [CrossRef]

24. Cai, Q.; Abdel-Aty, M.; Lee, J.; Eluru, N. Comparative analysis of zonal systems for macro-level crash modeling. J. Saf. Res. 2017, 61, 157-166. [CrossRef]

25. Basu, S.; Saha, P. Regression models of highway traffic crashes: A review of recent research and future research needs. Procedia Eng. 2017, 187, 59-66. [CrossRef]

26. Imran, M.; Nasir, N.A. Road Traffic Accidents. Prof. Med J. 2015, 22, 705-709.

27. Razali, M.S.M.A.; Zamzuri, Z. Modeling motorcycle road accidents with traffic offenses at several potential locations using negative binomial regression model in Malaysia. Int. J. Appl. Math. Stat. 2016, 54, 105-114.

28. Joshua, S.C.; Garber, N.J. Estimating truck accident rate and involvements using linear and Poisson regression models. Transp. Plan. Technol. 1990, 15, 41-58. [CrossRef]

29. Llau, A.F.; Ahmed, N.U.; Khan, H.M.; Cevallos, F.G.; Pekovic, V. The impact of red light cameras on crashes within Miami-Dade County, Florida. Traffic Inj. Prev. 2015, 16, 773-780. [CrossRef] [PubMed]

30. Bendak, S.; Alsharif, F. Crossing violations at traffic intersections with red light cameras in Dubai: A prospective study. Adv. Transp. Stud. 2019, 48, 112-121.

31. Carnis, L.; Kemel, E. Should I stay or should I go? Uncovering the factors of red light runnings in a field study. In Proceedings of the European Transport Conference 2012, Glasgow, Scotland, 8-10 October 2012. 